However, I recommend this book most highly for all interested in any aspect of blood supply, from donor to patient, including blood bankers, haematologists, surgeons and patient consumer societies; as well as politicians and economists. Mr Hagen is to be congratulated.

DR F E BOULTON

Deputy Director, Edinburgh E South-East Scotland Blood Transfusion Service, Royal Infirmary of Edinburgh.

\section{Medical Genetics Casebook}

Colleen D Clements, Clifton, New Jersey, The Humana Press Inc, 1982. $\$ 29.50$

Medical ethics is an emergent specialty, and the author believes that, like many people in the youthful phase of life, it is suffering from an identity crisis. It does not know of which parent it is the offspring - medicine? ethics? philosophy? It is uncertain of its real function - who it is addressing, who it is protecting, and it does not even know what questions it really should be asking. In this book, the author seeks to take this young upstart by the scruff of the neck and give it a meaning and purpose in life.

The root of the identity problem seems to lie in the enormous gulf which exists between theory and practice, between the armchair ethicist and the clinician. While both disciplines need to change their attitudes and conceptual frameworks, the author lays the bulk of the blame at the feet of the 'theoretician', who is particularly inflexible. $\mathrm{He}$ uses pre-existing structures and theories to meet the new situations with which he is confronted, and since these are static, they do not give any opportunity for change and growth. The author, a philosopher, has, for a prolonged period, been actively involved in the day-to-day workings of a medical genetics unit, and has observed how medicine, because it is clinical, is a 'self corrective process' and continuously changes to adapt itself to new situations. She has recognised the value of this to ethics so she has tried to apply it to this subject.

She describes cases from the medical genetics clinic (130 in all), then identifies the ethical issues, and finally uses systems theory to clarify the problems presented by the cases. This approach, starting with a clinical perspective and proceeding to the theoretical, is the opposite of that usually taken by ethicists.

The first chapter introduces some important areas - attitudes to pain and suffering, the use and abuse of information, the right use of scarce medical resources, undesirable side-effects of treatment, which are not, of course, unique to medical genetics. The next five chapters are much more specific, and are largely related to pre-natal diag; nosis. The worth of the individual, selective abortion, societal versus individual interests, perceptions of risk and the use of experimental and research procedures are amongst those considered. The final chapter elaborates the concepts and summarises the new approach to medical genetics which has been proposed and developed throughout the book.

Philosophy is a difficult subject for the outsider to grasp. The systems theory, which is the key to the study, for it is that which permits the introduction of the aspired-to flexibility, is explained ‘. . [it] attempts to remain in a controlled state, which involves mechanisms for maintaining swings and oscillations within certain limits sufficient to prevent such wild gyrations that the whole system breaks down. This is accomplished by feedback loops . . . . Later, when examining spontaneous abortion, killing is described as 'disrupting a homeostatic system composed of biotic material capable of being partially described on a reductive biochemical/ biophysical level'. If these sentences are your delight, then this book is for you. However, as a non-expert, I found page after page of such verbiage hard to take. I suspect this book will do better on the American market than in the UK, for Americans seem so attuned to this verbosity and jargon.

I cannot agree with the inscription on the flyleaf of the book 'that it will be of immense practical utility to the physician', but this is not to say physicians shouldn't read it. On the other hand, philosophers and ethicists will surely relish the intellectual challenge of this new working model for medical ethics, and medical students, if they are selective, could extract from it information on the wide range of medical problems encountered by a medical genetics unit and some of the more immediate ethical ramifications.

MARY J SELLER Paediatric Research Unit, The Prince Philip

Research Laboratories, Guy's Hospital Medical School, London
News and notes

\section{Money, justice and medical care}

Professor Bernard Williams will give the John Locke lecture at the Society of Apothecaries, Blackfriars Lane, London EC4 on Tuesday January 24 at $6 \mathrm{pm}$. The title will be: Money, justice and medical care. 